\title{
Avaliação das práticas diferenciais de amamentação: a questão da etnia*
}

\author{
Assessment of the differentiating practices in breast-feeding: the ethnic question
}

\author{
Marina Ferreira Rea**
}

\begin{abstract}
REA, M.F. Avaliação das práticas diferenciais de amamentação: a questão da etnia. Rev. Saúde Pública, 28: 365-72, 1994. Descreve-se a situação da prática de amamentar em duas áreas metropolitanas brasileiras: São Paulo e Recife, Brasil, em estudos conduzidos em 1987. Em amostras representativas da população de crianças saudáveis de 0-8 meses atendidas pelo sistema de saúde, notase que é maior em São Paulo a proporção das mães que iniciam a amamentação e a prevalência de amamentados. A duração média do aleitamento materno total (AM) e quase exclusivo (AE) é respectivamente de 127,5 e 66,6 dias em São Paulo. Em Recife, 104,4 e 31,7 dias, respectivamente, para AM e AE. Estudaram-se também os dados de amamentação conforme a cor da pele da mãe, concluindo que se amamenta mais em São Paulo do que em Recife, significativamente entre brancas. $O$ aleitamento materno quase exclusivo é praticado mais em São Paulo do que em Recife, por brancas e pardas. Observando-se os grupos étnicos em cada uma das cidades, notouse que são as mulheres não-brancas (pretas e pardas) aquelas que amamentam mais, sendo particularmente baixo o aleitamento quase exclusivo em Recife, maior entre as pretas ( 34,5 dias de mediana de $\mathrm{AE}$ ) comparado a 15,3 dias entre brancas e 16,7 entre pardas. O estudo aponta para a necessidade de se elaborar desenhos de pesquisa que levem em conta a questão da etnia e a amamentação, questão não respondida pela literatura em nível mundial.
\end{abstract}

Descritores: Aleitamento materno. Raças.

\section{Introdução}

A prática de amamentar tem sofrido importantes modificações nas áreas urbanas durante este século. Diversos estudos têm sido publicados a respeito, tanto em países desenvolvidos como naqueles em desenvolvimento (Notzon ${ }^{15}, 1984$; Martinez e Nalezienski ${ }^{8}, 1979$ ), mostrando que foram muitos os fatores envolvidos na queda do aleitamento materno.

* Baseado no projeto conduzido pelo Centro Brasileiro de Análise e Planejamento (CEBRAP), intitulado: "Avaliação do Programa Nacional de Aleitamento Materno", financiado pela Financiadora de Estudos e Projetos / FINEP (Processo $n^{\circ} 41.85 .0671 .00$ ) e pelo Instituto $\mathrm{Na}$ cional de Alimentação e Nutrição/TNAN/Ministério da Saúde, 1987; apresentado no VI Encontro Nacional da Associação Brasileira de Estudos Populacionais/ABEP, Olinda, 1988.

** Instituto de Saúde da Coordenadoria dos Institutos de Pesquisa da Secretaria de Estado da Saúde de São Paulo e do Centro Brasileiro de Análise e Planejamento (CEBRAP).

Separatas/Reprints: M.F. Rea - Rua Santo Antonio, 590 01314-000 - São Paulo, SP - Brasil

Edição subvencionada pela FAPESP. Processo 94/0500-0
Recentemente, já se registram tendências de reversão desta queda, seja nos países nórdicos (Helsing ${ }^{6}$, 1981), seja nos Estados Unidos (Martinez e Nalezienski $\left.{ }^{9}, 1981\right)$, ou mesmo em nosso meio (Monteiro e col. ${ }^{12}$, 1987).

Quando se observam os dados mundiais nota-se que a volta do aleitamento materno nos anos recentes é prevalente nas elites brancas e de alto nível escolar (Smith $^{20}$, 1984). Estudos que documentam esse retorno à prática de amamentar conforme cor da pele da mãe são poucos, alguns mostrando que tal tendência tem sido acompanhada pelas mulheres negras, porém apenas algumas vezes nos mesmos níveis que pelas brancas. Foi mostrado nos Estados Unidos, por exemplo, que em 1969 era de 19\% entre brancas e $9 \%$ entre negras a proporção de aleitamento materno exclusivo no início da vida, valores que foram para $51 \%$ e $25 \%$ em 1980 , respectivamente, em brancas e negras (Forman e col. ${ }^{4}, 1985$ ). É sabido que a população negra americana faz parte, de maneira geral, dos estratos de renda mais baixos da população. Assim, muitos desses estudos americanos não esclarecem se o fato de amamentar está ligado ao grupo étnico negro, ou apenas está sendo documentada mais uma característica da população de baixa renda. 
Em São Paulo, o retorno à prática de amamentar tem sido evidente em todos os estratos socioeconômicos (Monteiro e col. ${ }^{13}, 1988$ ), levando a crer que, entre outros fatores, os esforços conduzidos pelo Ministério da Saúde, com o Programa Nacional de Incentivo ao Aleitamento Materno, teve alguma repercussão nessa cidade (Rea e Berquó $\left.{ }^{18}, 1990\right)$ ). Aparentemente, a estratégia de utilização de campanhas pelos meios de comunicação de massa foi acertada, na medida em que permitiu o acesso de grandes contingentes da população a uma mensagem clara e de fácil entendimento.

A avaliação do citado Programa Nacional, com estudos conduzidos nas regiões metropolitanas de São Paulo e Recife, permitiu identificar alguns segmentos populacionais menos ou mais atingidos pelo Programa. As comparações das práticas alimentares infantis nas duas cidades mostram também que nem todos os grupos populacionais tiveram a mesma receptividade à política de incentivo à amamentação adotada pelas autoridades públicas, o que poderia ser o caso de alguns grupos étnicos - brancas, pretas e pardas - os quais, por razões distintas, parecem estar aleitando seus filhos de maneira diferente.

Este trabalho pretende analisar e dar subsídios ao entendimento das práticas diferenciais de amamentação conforme a cor da pele das mães, em São Paulo e Recife. Adverte-se que o desenho original do presente projeto não foi feito com a finalidade de estudar o aleitamento materno conforme grupos étnicos e que seus dados são originados de projetos conduzidos pelo Centro Brasileiro de Análise e Planejamento (CEBRAP) em 1987*.

\section{Metodologia}

Com a finalidade de avaliar o Programa Nacional de Incentivo ao Aleitamento Materno (PNIAM), foi delineada uma pesquisa tipo "antes-depois", ou seja, incluindo um levantamento da situação da amamentação imediatamente antes do início do Programa que serviria de base para a análise do impacto após este. Efetivamente o "antes" foi realizado em fevereiro/março de 1981 (Berquó e col. ${ }^{2}$, 1984) e o "depois", de maio/87 a agosto/88. O presente artigo relata apenas a análise dos dados realizada "depois" do Programa.

A avaliação da situação do aleitamento cobriu duas populações: mães e profissionais de saúde (pediatras, obstetras e pessoal de enfermagem)**. Os contextos escolhidos para a avaliação do Programa foram as regiões metropolitanas de São Paulo e Recife.

A população de estudo foi constituída por mães de crianças sadias de 0 a 8 meses, residentes na Grande São Paulo (GSP) e Região Metropolitana de
Recife (RMR) nos períodos de coleta de dados, em inquéritos realizados nos locais de atendimento à saúde.

Para a confecção da amostra, a população foi estratificada segundo a classe socioeconômica a que pertencia, cujos níveis foram definidos pela PNAD (Pesquisa Nacional por Amostragem de Domicílios), quais sejam, $76 \%, 17 \%$ e $7 \%$, correspondendo respectivamente, a proporções de baixa, média e alta renda.

A partir da listagem de unidades de saúde ou consultórios que atendem crianças sadias, em cada uma das cidades, foi feita amostragem ponderada e sistemática desses locais de atendimento (primeira etapa), para depois serem sorteadas as mães (segunda etapa). Crianças doentes não foram incluídas na amostra.

Foi utilizada partilha proporcional das mães, obtendo-se 3 estratos:

- a seleção do estrato 1 (baixo nível socioeconômico) foi feita dentre as mães que procuravam atendimento nas unidades de saúde estaduais, municipais e federais;

- a seleção do estrato 2 (médio nível socioeconômico) foi feita dentre as mães que procuravam atendimento nas unidades ou consultórios das previdências ou dos convênios;

- o estrato 3 (alto nível socioeconômico) foi selecionado através de mães que demandaram a consultórios privados, de medicina de grupo ou de convênios que dão atendimento particular.

A listagem das unidades ou consultórios foi obtida previamente, assim como sua demanda e número de turnos de atendimento. As entrevistas foram feitas nos locais de atendimento de saúde sorteados, e respondidas sempre pela própria mãe da criança.

O formulário utilizado continha, entre outras, questões específicas para avaliação das ações do Programa, particularmente quanto ao papel da propaganda pró-amamentação e dos serviços de saúde.

As variáveis dependentes coletadas e aqui analisadas são:

- ter iniciado a amamentação;

- duração do aleitamento materno total (AM);

- duração do aleitamento materno quase exclusivo $(\mathrm{AE})^{* * *}$;

* Os relatórios completos encontram-se na biblioteca do CEBRAP e nas instituições financiadoras (UNICEF, FINEP e Secretaria de Ciência e Tecnologia do Ministério da Saúde).

** No presente artigo apenas será analisada a população de mães.

*** Aqui definido como o uso do leite materno como única fonte láctea de alimento para a criança; permite a inclusão de quaisquer outros líquidos ou semi-sólidos desde que não preparados com leite artificial. 
- proporção de crianças amamentadas aos 1,4 e 6 meses.

$E$ as seguintes variáveis independentes:

- cor da pele;

- renda familiar percapita;

- escolaridade do pai;

- escolaridade da mãe;

- mãe trabalhar fora do lar;

- idade da mãe;

- paridade;

- ter visto a Campanha pró-amamentação.

Destacamos que, as formas de perguntar sobre 0 aleitamento materno, o desmame e o aleitamento materno quase exclusivo, assim como as conceituações desses termos foram definidos previamente. AM ou "aleitamento materno total" significa ter recebido leite materno independentemente de qualquer outro alimento líquido. Desmame significa a interrupção dessa prática.

Com relação à coleta de dados de cor da pele, considerando a dificuldade em definir os grupos étnicos, optou-se por treinar os entrevistadores a anotar a cor das entrevistadas, sem que lhes fosse feita a pergunta. Tentando padronizar essa avaliação, tomou-se como exemplo pessoas conhecidas como atores, cantores, e outros, e verificou-se que a classificação por cor não era igual em um primeiro momento. A partir daí, procurou-se definir os grupos étnicos segundo várias características, orientando o entrevistador a considerar "pardas" todas aquelas que apresentassem qualquer traço de mestiçagem.

\section{Análise dos dados}

O método estatístico utilizado para a análise dos dados foi a tábua de vida, onde as medianas de duração do aleitamento ( $\mathrm{AM}$ ou $\mathrm{AE}$ ) e algumas proporções em momentos escolhidos são apresentadas.

A análise dos dados conforme cor da pele será feita comparando-se São Paulo com Recife.

A escolha do método das tábuas de vida e da mediana para estudos de aleitamento materno já foram justificadas por ( $\left.\operatorname{Rea}^{16}, 1981\right)$, destacando-se as vantagens principais:

- podem ser analisadas ao mesmo tempo tanto as crianças já desmamadas ("eventos" da tábua), como as ainda amamentadas e as que não tinham idade suficiente para serem observadas por todo o período ("dados censurados" da tábua);

- embora a coleta de dados tenha sido transversal, a análise pode ser feita de forma longitudinal e as "curvas de amamentação" produzidas ficam mais "suavizadas", permitindo evitar-se os picos ou declives devido às costumeiras preferências por dígitos (3, 6 , etc.). Com isso, chega-se mais perto da realidade, como se fosse em estudo prospectivo;
- o cálculo da medida de tendência central - a mediana - ou seja, a idade onde ainda $50 \%$ das crianças estavam amamentadas - contém informações de amamentadas e desmamadas, sendo mais adequado para expressar a distribuição não normal do desmame. Quando se utiliza a média levam-se em conta valores de duração pouco prevalentes ou aberrantes de mães que amamentam por longos períodos;

- permite a comparação das proporções de crianças amamentadas em idades selecionadas (1, 4 e 6 meses), conforme sejam residentes em São Paulo ou Recife, e de acordo com algumas características, por exemplo, segundo a cor da pele de suas mães.

Foram executados modelos de análise tábuas de vida ("life table analysis"), conforme programa SPSS (Nie e col ${ }^{14}, 1975$ ): as diferenças entre as proporções de amamentados serão expressas em percentuais de aumento ou diminuição da amamentação, e as diferenças entre as medianas serão expressas em dias. Foram também executadas tábuas de vida conforme o programa BMDP com os testes "generalized Wilcoxon - Breslow e Savage - Mantel - Cox", para testar as proporções de amamentados - teste das curvas (Breslow ${ }^{3}, 1984$ ).

\section{Resultados e Comentários}

$O$ aleitamento materno total e quase exclusivo nas áreas metropolitanas de São Paulo e Recife

Foram obtidos resultados de 380 mães residentes em São Paulo e 355 em Recife. A composição das duas amostras conforme extrato de renda nas duas cidades é bastante distinta.

A Tabela 1 reúne algumas características selecionadas das amostras. Nota-se que a população de Recife é mais pobre e de mais baixa escolaridade que aquela de São Paulo: tem-se $40,5 \%$ de famílias com renda per capita até $1 / 4$ do salário mínimo em Recife, enquanto é de cerca de $6 \%$ essa proporção em São Paulo. Como se sabe que a amostragem obedeceu os mesmos critérios em ambas as cidades, parece que ou os serviços de saúde que captam a população de baixa renda em São Paulo estiveram pouco representados, ou seja, a população mais pobre não frequienta as unidades de saúde pública que foram incluídas na amostra, ou há, de fato, muito menos pessoas de baixa renda em São Paulo do que em Recife. Consulta a dados secundários de pesquisas do IBGE confirma esta última afirmação.

Com relação à escolaridade, além de ser maior a proporção de homens e mulheres com baixa escolaridade em Recife, é notável a maior proporção de pessoas com nível superior nesta cidade na 
Tabela 1 - Características das amostras estudadas. Grande São Paulo(GSP) e Região Metropolitana de Recife(RMR), 1987

\begin{tabular}{|c|c|c|}
\hline Características & GSP & RMR \\
\hline $\begin{array}{l}\text { Renda per capita } \\
\text { até } 0,24 \mathrm{SM} \\
0,25 \text { a } 0,49 \mathrm{SM} \\
0,5 \text { a } 0,99 \mathrm{SM} \\
1 \text { e mais SM }\end{array}$ & $\begin{array}{r}5,7 \\
23,8 \\
34,1 \\
36,4\end{array}$ & $\begin{array}{l}40,5 \\
28,0 \\
15,2 \\
16,3\end{array}$ \\
\hline $\begin{array}{l}\text { Escolaridade da mãe } \\
\text { menor que } 4 \text { anos } \\
4 \text { a } 7 \text { anos } \\
8 \text { a } 10 \text { anos } \\
11 \text { e mais anos }\end{array}$ & $\begin{array}{l}27,6 \\
43,9 \\
17,4 \\
11,1\end{array}$ & $\begin{array}{l}40,9 \\
24,7 \\
13,1 \\
21,3\end{array}$ \\
\hline $\begin{array}{l}\text { Escolaridade do companheiro } \\
\text { menor que } 4 \text { anos } \\
4 \text { a } 7 \text { anos } \\
8 \text { a } 10 \text { anos } \\
11 \text { e mais anos }\end{array}$ & $\begin{array}{l}26,8 \\
36,6 \\
22,9 \\
13,7\end{array}$ & $\begin{array}{l}32,8 \\
25,4 \\
16,4 \\
25,4\end{array}$ \\
\hline Mãe trabalha fora de casa & 22,2 & 18,9 \\
\hline $\begin{array}{l}\text { Idade da māe } \\
\text { menor de } 20 \text { anos } \\
20 \text { a } 29 \text { anos } \\
30 \text { e mais anos }\end{array}$ & $\begin{array}{l}14,0 \\
66,8 \\
19,3\end{array}$ & $\begin{array}{l}21,6 \\
58,8 \\
19,6\end{array}$ \\
\hline Primiparas & 42,4 & 46,5 \\
\hline $\begin{array}{l}\text { Cor } \\
\text { brancas } \\
\text { pretas }>\text { negras } \\
\text { pardas }>\text { nard }\end{array}$ & $\begin{array}{r}60,1 \\
8,2 \\
31,6\end{array}$ & $\begin{array}{l}35,0 \\
11,0 \\
54,0\end{array}$ \\
\hline Viu campanha pró-amamentação & 66,6 & 71,9 \\
\hline$N$ & 380 & 355 \\
\hline
\end{tabular}

SM = Salário Mínimo

presente amostra.

É evidente a maior proporção de mães adolescentes em Recife, e também aquelas que estão tendo seu primeiro filho. A proporção que trabalha fora de casa parece semelhante nas duas cidades, ligeiramente maior em São Paulo.

É semelhante a proporção de mulheres expostas à campanha pró-amamentação nas duas cidades, ligeiramente maior em Recife.

Quanto à cor da pele, nota-se também que em Recife é maior a proporção da população de origem negra (soma de pretas e pardas), ou seja, a população negra chega a $65 \%$, comparada a $40 \%$ em São Paulo. Análise desta população por estrato de renda mostrou que ela se encontra majoritariamente concentrada nos níveis 1 (baixa renda): $83 \%$ no caso de Recife e 77,1\% no caso de São Paulo.

Pelos dados aqui apresentados, pode-se afirmar que São Paulo e Recife não constituem realidades muito similares no que diz respeito à amostra estudada de mães de crianças menores de 8 meses. Desta forma, analisou-se em separado a prática do aleitamento comparando-se São Paulo com Recife, privilegiando a categoria cor da pele, com a finalidade de sinalizar pontos que permitam futuro aprofundamento.

Os resultados apontados às Tabelas 2 e 3 mostram resumidamente, os padrões gerais de aleitamento nessas duas áreas metropolitanas brasileiras, quais sejam:

a) grande número de mães inicia a amamentação tanto em São Paulo $(96,1 \%)$ como em Recife $(93,8 \%)$, fato comparável a outras regiões subdesenvolvidas do mundo. Nota-se que a proporção de mães que inicia a amamentação em São Paulo tende a ser maior que em Recife;

b) a proporção de crianças de $0-8$ meses amamentadas no momento também tende a ser maior em São Paulo do que em Recife (62 x 51\%);

c) a duração média do aleitamento materno total é de cerca de 4 meses (127,5 dias) em São Paulo, enquanto que, em Recife, é de cerca de 3 meses e meio (23,1 dias a menos);

d) a duração média do aleitamento materno quase exclusivo por sua vez é mais que o dobro em São Paulo comparado a Recife (66,6 x 31,7 dias).

Assim, pode-se dizer que o padrão de aleitamento nas duas áreas urbanas brasileiras estudadas seja comparável à situação de outras áreas subdesenvolvidas urbanas do mundo: alta proporção de mães iniciam a amamentação, mas desmamam precocemente após a introdução bastante precoce de leite artificial. Este quadro mostrou melhora após o PNIAM (Rea e Berquó $\left.{ }^{18}, 1990\right)$ mas, ainda há muito o que fazer na promoção da amamentação no país, particularmente quanto ao prolongamento da amamentação exclusiva que, conforme recomendação da OMS e UNICEF, deve ser praticada até 4 a 6 meses de vida* sendo desnecessário inclusive 0 uso de qualquer

Tabela 2 - Proporção de mães que iniciaram a amamentação (AM) $\ominus$ daquelas que estavam amamentando no momento da entrevista. Grande São Paulo(GSP) e Região Metropolitana de Recife(RMR), 1987

\begin{tabular}{lcc}
\hline Amamentação & GSP & RMR \\
\hline Iniciaram AM & 96,1 & 93,8 \\
Prevalência & 62,2 & 51,0 \\
\hline $\mathrm{N}$ & 380 & 355 \\
\hline
\end{tabular}

Tabela 3 - Duração média (em dias) da amamentação total e quase exclusiva. Grande São Paulo(GSP) e Região Metropolitana de Recife(RMR), 1987

\begin{tabular}{lrr}
\hline Amamentação & GSP & RMR \\
\hline AM & 127,5 & 104,4 \\
AE & 66,6 & 31,7 \\
\hline $\mathrm{N}$ & 380 & 355 \\
\hline
\end{tabular}

* OMS/UNICEF - Declaração de Innocenti: sobre a proteção, promoção e apoio ao aleitamento materno. Florença, Itália, 1990. (Folder). 
outro líquido, nem mesmo água ou chá (Martinez e col. $\left.{ }^{10}, 1992\right)$.

Diferentemente de programas centrados em instituições, como os de Costa Rica (Puriscal), Filipinas (Baguio) e tantos outros (Jellife e Jellife ${ }^{7}, 1988$ ), o Programa brasileiro pró-amamentação teve caráter amplo, multi-institucional e multisetorial. Marin e Oliveira, citados por Jellife e Jellife ${ }^{7}(1988)$ descrevem as principais atividades levadas a efeito pelo Programa no período de 1980 a 1987, quais sejam, uso estruturado e planejado dos meios de comunicação de massa, criação de 1.500 grupos de mães, 2 concursos de fotografias e competições escolares envolvendo 6.000 crianças, adoção de alojamento conjunto por $60 \%$ das maternidades governamentais, entre outras. Não destacam, entretanto, diferenças entre atividades ocorridas ou em São Paulo ou em Recife, que poderiam apontar maior engajamento no Programa de uma ou outra cidade. A avaliação realizada pelo CEBRAP* mostrou, por exemplo, mais mudança em nível da prática hospitalar em Recife: 0 alojamento conjunto passou de $36 \%$ a $51 \%$ (inquéritos de 1981 e 1987, respectivamente) enquanto em São Paulo permaneceu em cerca de $9 \%$; e a primeira mamada antes de $11 \mathrm{~h}$ pós-parto foi de $11 \%$ para $29 \%$ em Recife, enquanto em São Paulo era de $22 \%$, em 1981 , tendo permanecido igual. Somente estas mudanças estruturais ou de práticas hospitalares (quase $100 \%$ dos nascimentos se dão em hospitais em ambas as cidades) não seriam suficientes para explicar essa visível vantagem de São Paulo nas práticas de amamentar, mesmo porque Recife apresentou mudanças estruturais pró-amamentação mais evidentes. Sem dúvida os diferenciais apontados na Tabela 1 quanto às características da população dão algumas pistas: a população de Recife é mais pobre, é menos escolarizada e há mais mães jovens abaixo de 20 anos, fatores em geral determinantes de desmame precoce. Como as mães de Recife referem ter visto um pouco mais a Campanha pró-amamentação do que as de São Paulo ( $72 \times 67 \%$ ), estes dados foram testados e notou-se que esta diferença não era significativa. Estariam então, os presentes dados, confirmando o que vem sendo descrito na literatura: amamentação ocorre mais entre mulheres educadas, de melhor renda, não adolescentes? $E$ a questão da cor da pele?

Aleitamento materno em São Paulo "versus" Recife, controlando-se a cor da pele

Utilizando-se o método das tábuas de sobrevida, observa-se que a proporção das mães que iniciam a amamentação é semelhante (mais de $94 \%$ ) nas dife-

* Relatório Final rentes etnias tanto em São Paulo como em Recife.

Quando se comparam as durações e a proporção de amamentados nas duas cidades conforme cor da pele da mãe, nota-se, considerando-se apenas as brancas, que é significativamente maior em São Paulo a duração do aleitamento materno total $(\mathrm{P}<$ $0,04)$ e quase exclusivo $(P<0,000)$. Na Tabela 4 , nota-se que as brancas, em São Paulo, amamentam cerca de um mês a mais do que as de Recife. No caso do aleitamento materno quase exclusivo (Tabela 5), nota-se que a diferença de duração mediana é cerca de um mês e meio maior em São Paulo do que em Recife. Tal diferença no $\mathrm{AE}$ é também notável no primeiro mês de vida, quando $66,9 \%$ das mães brancas estão amamentando quase exclusivamente em São Paulo, mas apenas $42,3 \%$ daquelas de Recife. No quarto mês de vida, restam apenas $3,9 \%$ de mães aleitando quase exclusivamente em Recife. Destaque-se que isto ocorre entre as mulheres brancas, aquelas que, já dissemos, estão entre os melhores estratos de renda da população.

Quando se consideram apenas mulheres pretas, embora os números sejam pequenos (31 em São Paulo e 38 em Recife), nota-se que a duração mediana da amamentação é também, como entre as brancas, maior em São Paulo do que em Recife $(138 \times 114$ dias), com exceção do primeiro mês de vida (Tabela 6). Essas diferenças entretanto, não são significativas.

Tabela 4 - Duração mediana da amamentação e proporção de amamentados aos 1, 4 e 6 meses entre mulheres brancas. Grande São Paulo(GSP) e Região Metropolitana de Recife(RMR), 1987

\begin{tabular}{lrcc}
\hline Duração & GSP & RMR & $\begin{array}{c}\text { Diferença* } \\
\text { GSP RMR }\end{array}$ \\
\hline 1 mês & 83,2 & 79,8 & $3,4 \%$ \\
4 meses & 49,4 & 34,0 & $15,4 \%$ \\
6 meses & 38,5 & 21,6 & $16,9 \%$ \\
mediana & 117,5 & 82,4 & 35,1 dias \\
\hline Total $(\mathrm{N})$ & 226 & 121 & - \\
\hline
\end{tabular}

*Significativa

Tabela 5 - Aleitamento materno quase exclusivo: duração mediana e proporção de crianças aos 1,4 e 6 meses entre mulheres brancas. Grande São Paulo(GSP) e Região Metropolitana de Recife(RMR), 1987

\begin{tabular}{lcrc} 
Duração & GSP & RMR & $\begin{array}{c}\text { Diferença* } \\
\text { GSP RMR }\end{array}$ \\
\hline 1 mês & 66,9 & 42,3 & $24,6 \%$ \\
4 meses & 27,2 & 3,9 & $23,3 \%$ \\
6 meses & 12,7 & 1,0 & $11,7 \%$ \\
mediana & 63,7 & 15,3 & 48,4 dias \\
\hline Total (N) & 226 & 121 & - \\
\hline "Significativa & & &
\end{tabular}


Tabela 6 - Duração mediana da amamentação e proporção de amamentados aos 1, 4 e 6 meses entre mulheres pretas. Grande São Paulo(GSP) e Região Metropolitana de Recife(RMR), 1987

\begin{tabular}{lrrc}
\hline Duração & GSP & RMR & $\begin{array}{c}\text { Diferença* } \\
\text { GSP RMR }\end{array}$ \\
\hline 1 mês & 83,7 & 94,6 & $-10,9 \%$ \\
4 meses & 58,7 & 45,5 & $13,2 \%$ \\
6 meses & 44,9 & 36,4 & $8,5 \%$ \\
mediana & 137,9 & 113,6 & 24,3 dias \\
\hline Total (N) & 31 & 38 & - \\
\hline
\end{tabular}

* Não significativa

Tabela 7 - Aleitamento materno quase exclusivo: duração mediana e proporção de crianças aos 1,4 e 6 meses entre mulheres pretas. Grande São Paulo(GSP) e Regiāo Metropolitana de Recife(RMR), 1987

\begin{tabular}{lrrc}
\hline Duração & GSP & RMR & $\begin{array}{c}\text { Diferença* } \\
\text { GSP RMR }\end{array}$ \\
\hline 1 mês & 71,0 & 54,5 & $16,5 \%$ \\
4 meses & 24,4 & 8,6 & $15,8 \%$ \\
6 meses & 13,6 & - & $13,6 \%$ \\
mediana & 65,9 & 34,5 & 31,4 dias \\
\hline Total $(\mathrm{N})$ & 31 & 38 & - \\
\hline
\end{tabular}

Não significativa

No caso do aleitamento materno quase exclusivo entre as pretas, também é superior a proporção das que amamentam em São Paulo, encontrando-se diferença de duração mediana de 31,4 dias, quando comparadas às de Recife (66 x 34,5 dias) (Tabela 7, dados não significativos).

Quando se comparam as mulheres pardas de ambas as cidades nota-se que, embora aparentemente superior as proporções de amamentados em São Paulo com relação a Recife (Tabela 8), esta diferença é apenas significativa no caso do aleitamento materno quase exclusivo $(P<0,000)$. Neste caso, já com um mês de vida, mais da metade das mães estão dando outros alimentos, e com 4 meses, é de apenas $6 \%$ a proporção de crianças quase exclusivamente amamentadas, valor similar àqueles encontrados para crianças brancas (4\%) e pretas (9\%) (Tabela 9). Esta análise corre na mesma direção quando juntamos pardas e pretas.

Em resumo, quando se comparam as duas áreas metropolitanas, dentro de cada grupo étnico, a prática do aleitamento materno quase exclusivo é maior em São Paulo do que em Recife, em todos os grupos de mulheres, significativamente entre brancas e pardas. Entretanto, só há diferença na prática do aleitamento materno total para as mulheres brancas, onde é novamente em São Paulo que se amamenta mais.

Uma outra forma de análise foi feita para o conjunto de mulheres dentro de cada cidade
Tabela 8 - Duração mediana da amamentação e proporção de amamentados aos 1,4 e 6 meses entre mulheres pardas. Grande São Paulo(GSP) $\theta$ Região Metropolitana de Recife(RMR), 1987

\begin{tabular}{lccc}
\hline Duração & GSP & RMR & $\begin{array}{c}\text { Diferença* } \\
\text { GSP RMR }\end{array}$ \\
\hline 1 mês & 88,9 & 84,1 & $4,8 \%$ \\
4 meses & 56,4 & 44,5 & $11,9 \%$ \\
6 meses & 46,6 & 32,5 & $14,1 \%$ \\
mediana & 156,3 & 99,0 & 57,3 dias \\
\hline Total $(\mathrm{N})$ & 119 & 187 & - \\
\hline
\end{tabular}

*Nāo significativa

Tabela 9 - Aleitamento materno quase exclusivo: duração mediana e proporçāo de crianças aos 1,4 e 6 meses entre mulheres pardas. Grande São Paulo(GSP) e Regiāo Metropolitana de Recife(RMR), 1987

\begin{tabular}{lcrc}
\hline Duração & GSP & RMR & $\begin{array}{c}\text { Diferença } \\
\text { GSP RMR }\end{array}$ \\
\hline 1 mês & 74,4 & 41,5 & $32,9 \%$ \\
4 meses & 32,2 & 6,0 & $26,2 \%$ \\
6 meses & 19,0 & 2,2 & $16,8 \%$ \\
mediana & 72,1 & 16,7 & 55,4 dias \\
\hline Total (N) & 119 & 187 & - \\
\hline
\end{tabular}

"Significativa

conforme cor da pele.

Observando-se as Figuras 1 e 2, e concentrando a atenção em São Paulo, nota-se que, comparando-se brancas, pretas e pardas, a duração da amamentação é menor entre as mulheres brancas. Em Recife, observa-se também menor duração de amamentação entre brancas. No caso do aleitamento materno quase exclusivo, não há diferenças em São Paulo nos diferentes grupos de cor. A duração extremamente baixa do aleitamento materno quase exclusivo em Recife, caracteriza introdução precoce da mamadeira, que é pior entre brancas e pardas (cerca de 15 dias) mas ainda baixo entre pretas (cerca de 30 dias).

Os estudos encontrados na literatura sobre a prática da amamentação e a cor da pele não caminham todos na mesma direção. Dados dos Estados Unidos (1988) mostram que é o dobro a proporção de mães brancas que amamentam (62\%) comparadas às negras (30\%) (Brown citado por Jellife e Jellife $^{7}, 1988$ ).

A amamentação mais prolongada entre mulheres brancas foi mostrada em outra área urbana, em Oakland, na Califórnia. Foram estudadas 615 mulheres: entre as brancas, $82 \%$ saiam amamentando da maternidade e $21 \%$ ainda amamentavam com 4 meses de vida do bebê; no caso das negras, esses percentuais foram, respectivamente, de $52 \%$ e $5 \%$ (Samuels ${ }^{19}, 1981$ ).

Em um bairro de Londres, entretanto, (Hall e 


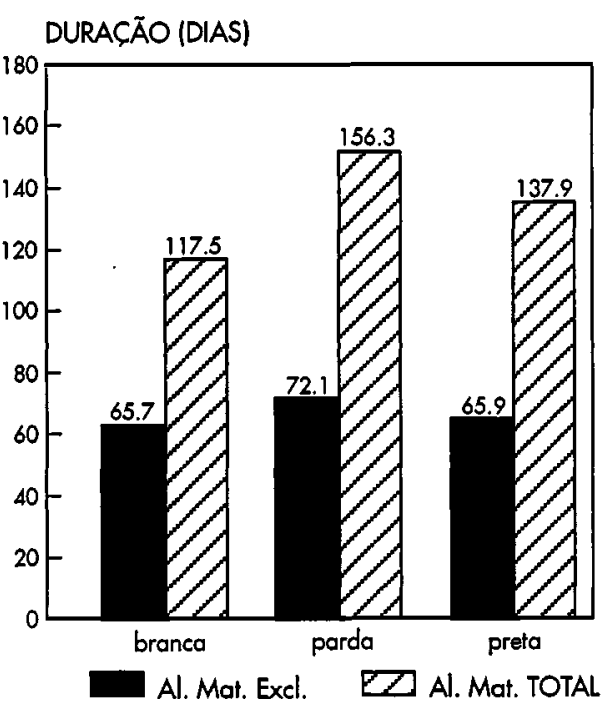

Figura 1. Duração mediana do aleitamento materno em mulheres brancas, pardas e pretas. Grande São Paulo, 1987

$\left.\operatorname{col}^{5}{ }^{5}, 1985\right)$ mostram que a proporção de mães negras amamentando era significativamente maior do que de brancas, tanto à saída da maternidade como na sexta semana de vida. Esses autores foram dos poucos que reafirmaram a importância da questão da etnia no estudo da prática de alimentar a criança.

Por sua vez, Andrew e col. ${ }^{1}$ (1984), estudando mães de Nova Yorque, não encontraram relação entre amamentação e grupos étnicos.

No caso do Brasil, a relação entre amamentação e cor já havia sido estudada por Thomson ${ }^{21}, 1975$, em Londrina, mostrando que entre 704 mulheres entrevistadas, não houve diferenças entre o aleitamento de brancas e não-brancas. Em Campinas, próximo a essa mesma época, Martins Filho ${ }^{11}$, constatou uma superioridade de 3 meses na mediana de aleitamento materno total de não-brancas quando comparadas às brancas. Os presentes dados, em São Paulo, mostram cerca de um mês de duração maior entre não-brancas; como eles foram colhidos pouco mais de 10 anos depois, isto poderia estar indicando tendência de aproximação das práticas da amamentação independente da cor? Procurando estudar essa tendência, utilizando-se dos resultados do presente projeto, foi feita uma análise da amamentação dos filhos anteriores das mães multíparas ${ }^{17}$. A proporção dos filhos amamentados por mais de 6 meses cresceu entre as brancas desde $21 \%-31 \%-38 \%$, respectivamente entre 1982 e 1984 , caindo a $20 \%$ em 1986. Na população negra (pretas e pardas) as proporções nos mesmos períodos foram de $16 \%, 37 \%$, $36 \%$ e $37 \%$, em 1986, isto é, mostrando que entre negras a amamentação vem se mantendo de forma

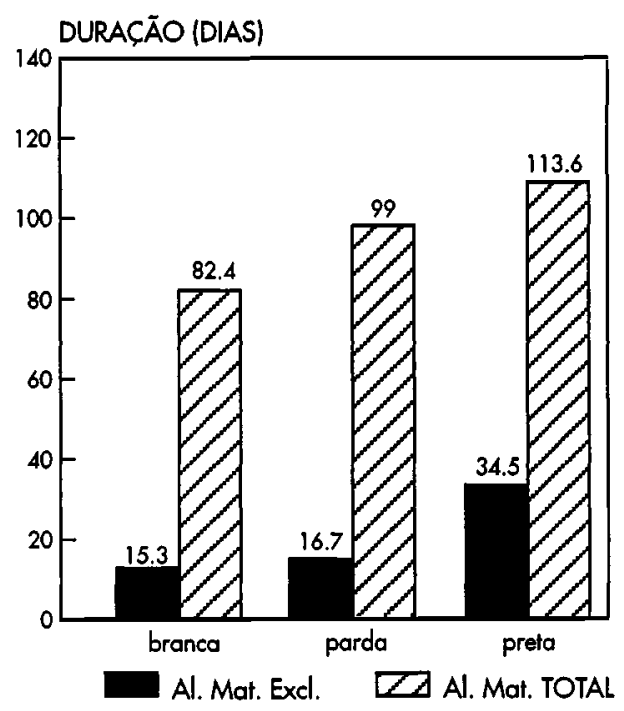

Figura 2. Duração mediana do aleitamento materno em mulheres brancas, pardas e pretas. Regiāo Metropolitana de Recife, 1987

mais prolongada, independentemente da diminuição da atividade do Programa Pró-Aleitamento Materno cujo auge foi nos anos de 1982 a 1984.

Estudo conduzido pelo INAN (Instituto Nacional de Alimentação e Nutrição/Ministério de Saúde), em 1989*, com amostra realizada pelo IBGE em todo o Brasil, identificou uma população de $52 \%$ de pardas, $41,6 \%$ de brancas, $5,7 \%$ de pretas e $0,5 \%$ de amarelas, entre 6.058 famílias estudadas. Embora haja diferenças nestas informações quanto à amamentação (que tanto podem ter sido dadas pela mãe como pelo chefe de família) com os presentes dados (onde sempre a informante foi a mãe), e nas formas de identificar a cor da pele (o IBGE anota conforme a auto-avaliação da cor), foi encontrado quanto a amamentação que:

- não há diferenças entre brancas, pretas e pardas quanto à proporção das que iniciam a amamentação (varia de 88,4 a 89,5\%), mas apenas entre amarelas (100\% iniciaram);

- duração média do aleitamento materno total foi de 5,6 meses entre brancas, 6,5 entre pretas e 6,5 entre pardas. A duração mediana também mostrouse menor entre brancas ( 3 meses, enquanto foi de 4,0 meses tanto para pretas como para pardas).

Assim, esse amplo estudo de base populacional comportou-se na mesma direção do presente trabalho, cuja amostra foi colhida de mães em unidades de saúde de duas capitais brasileiras. Concluindo: a

\footnotetext{
* IBGE/INAN/IPLAN/IPEQ - Pesquisa Nacional sobre Saúde e Nutrição - PNSN, 1989. Dados inéditos.
} 
duração da amamentação é menor entre brancas no nosso país, notando-se também que, em Recife, esta duração é menor que os dados nacionais em todos os grupos étnicos.

O presente trabalho permitiu perceber como se conhece pouco sobre as diferentes práticas de alimentação infantil nos grupos étnicos brasileiros; não se sabe como elas têm se modifícado e se são influenciadas por programas ou políticas públicas. Estudos feitos em outros países tampouco esclarecem a questão. No caso da amamentação, as negras têm características biológicas que, aliadas ao apoio social e à orientação médica adequada poderiam resultar em sucesso do aleitamento materno. Entretanto, não se conhecem vários aspectos dessa prática: as mulheres negras têm menos ou mais complicações no pósparto que as brancas? Menos ou mais mastites, fissuras de mamilos, outras ocorrências? Menos ou mais apoio em seu grupo de referência (família, amigos)? Menos ou mais crendices, vontade de imitar o "moderno" e usar mamadeira? Estariam amamentando mais para evitar comprar leite artificial, já que se trata de população mais pobre? São mal atendidas pelos serviços de saúde, recebendo menos apoio e orientação? Qual o melhor método de investigação para o estudo da amamentação conforme grupos étnicos? Estas e outras questões merecem investigação específica na população conforme etnia.

REA, M.F. [Assessment of the differentiating practices in breast-feeding: the ethnic question\}. Rev Saúde Pública, 28:365-72, 1994. Breastfeeding practices in two Brazilian metropolitan areas (S. Paulo and Recife) are described, as part of a study carried out in 1987. In a random sample of healthy 0.8 month old infants, selected from all health care units, higher breastfeeding rates were found in S. Paulo (initiation, prevalence, median and average) than in Recife. The mean duration of breastfeeding, mixed and full, was of 127.5 and 66.6 days, respectively, for S. Paulo, and of 104.4 and 31.7 days for Recife. When data are analysed according to ethnic group, white S. Paulo women breastfeed more than white Recife women. Full breastfeeding rate is more prevalent among white and "mulato" S. Paulo women. However, when the data were analyzed for each city separately, it was found, remarkably, that the non-whites breastfeed more than the whites. In Recife, full breastfeeding is particularly low in whites (of 15.3 days median) and "mulatos"(of 16.7 days), but of 34.5 days in blacks. The study points out the need for greater in-depth investigation of the issue of ethnicity and infant feeding practices, still inadequately understood in world literature.

\section{Referências Bibliográficas}

1. ANDREW, F.M. et al. Infant feeding practices of families belonging to a prepaid group practice health care plan. Pediatrics, 65:978-88, 1980

2. BERQUÓ, E. et al. Caracterização e determinantes do aleitamento materno na Grande São Paulo. São Paulo, CEBRAP 1984. (Cadernos CEBRAP, 2 - Nova Série).

3. BRESLOW, N. Comparison of survival curves. In: Buyse, M.E.; Staquer, M.J.; Sylvester, R. Cancer clinical trials, methods and practice. Oxford, Oxford University Press, 1984. p. 381-406.

4. FORMAN, M.R. et al. Exclusive breast-feeding of newborns among married women in the United States: the national natality survey of 1969 and 1980 . Am.J.Clin.Nutr., 42:8649, 1985.

5. HALL, D.I. et al. Breast-feeding: differences in prevalence between caucasian and negroid women resident in Paddington and North Kensington, London, England. J.Adv. Nurs., 10: 173-7, 1985.

6. HELSING, E. Infant feeding practices in Northern Europe. Assig. Child., 55/56:73-89, 1981.

7. JELLIFFE, D.B. \& JELLIFFE, E.F.P., ed. Programmes to promote breast-feeding. Oxford, Oxford Medical Publ., 1988.

8. MARTINEZ, G.A. \& NALEZIENSKI, J.P. The recent trend in breast-feeding. Pediatrics, 66:686-92, 1979.

9. MARTINES, G.A. \& NALEZIENSKI, J.P. 1980 update: the recent trend in breast-feeding. Pediatrics, 67:260-3, 1981 .

10. MARTINES, J. et al. Breast-feeding in the first 6 months: no need for extra fluids. Br.Med.J., 304:1068-9, 1992.

11. MARTINS FILHO, J. Contribuição ao estudo do aleitamento matemo em Campinas. Campinas, 1976. [Tese de Livre Docência - Faculdade de Ciências Médicas da Universidade Estadual de Campinas].

12. MONTEIRO, C.A. et al. The recent revival of breast-feeding in the city of São Paulo, Brazil. Am.J.Public Health, 77:964. $6,1987$.

13. MONTEIRO, C.A. et al. Breast-feeding patterns and socioeconomic status in the city of São Paulo. J.Trop.Pediatr., 34:186-92, 1988.

14. NIE, N.H. et al. SPSS - statistical package for the social sciences. New York, McGraw-Hill, 1975

15. NOTZON, F. Trends in infant feeding in developing countries. Pediatrics, 74 (Suppl.):648-66, 1984.

16. REA, M.F. Aleitamento materno em núcleos rurais do Vale do Ribeira, São Paulo. São Paulo, 1981. [Disșertação de Mestrado - Faculdade de Medicina da USP].

17. REA, M.F. Amamentação na população de raça negra em São Paulo. In: Encontro Nacional de Estudos Populacionais, $6^{\circ}$, Olinda, 1988. Anais. São Paulo, Associação Brasileira de Estudos Populacionais, 1988. v.3. p. 393-410.

18. REA, M.F. \& BERQUÓ, E.S. Impact of the Brazilian National Breast-feeding Programme on the mothers in Greater São Paulo. Bull. World Health Organ., 68: 365-71, 1990.

19. SAMUELS, S. Socio-cultural obstacles to breast-feeding in American community. Berkeley, 1981. [Dissertation for Doctor Degree in Public Health - University of California].

20. SMITH, D.P. Breast-feeding in the United States. Soc.Biol., 32:53-60, 1984

21. THOMSON, Z. Estudo de prática do aleitamento materno em um grupo populacional Londrina, PR. J.Pediatric, 45: 379-85, 1978.

Recebido para publicação em 2.3 .94 Aprovado para publicação em 11.8 .94 